\title{
Numerical Study of Airfoil Stall Cells Using a Very Wide Computational Domain
}

\author{
Luca Manni \\ Department of Industrial Engineering, University of Rome Tor Vergata, Rome 00173, Italy \\ Takafumi Nishino and Pierre-Luc Delafin \\ Centre for Offshore Renewable Energy Engineering, Cranfield University, Cranfield, Bedfordshire \\ MK43 OAL, United Kingdom
}

\begin{abstract}
The formation of stall cells over a NACA 0012 airfoil at a Reynolds number of one million has been investigated numerically, using unsteady Reynolds-averaged Navier-Stokes (URANS) and delayed detached-eddy simulation (DDES) approaches. The simulations are performed with a very wide computational domain (10 chord length) to minimize the influence of spanwise periodic boundary conditions. For the URANS simulations, four different spanwise mesh resolutions are tested to determine the minimum resolution required to capture the formation of stall cells. Both URANS and DDES results show a sudden decrease in lift and increase in drag between $16^{\circ}$ and $17^{\circ}$ angle of attack, accompanied by a significant change of separated flow patterns. Stall cell structures are observed clearly in the URANS solutions between $17^{\circ}$ and $19^{\circ}$ with a spanwise spacing of about 1.4 to 1.8 chord length, which agrees well with a theoretical prediction based on the slope of the lift curve in this angle-of-attack range. The DDES results show much more complex flow patterns over the airfoil at these high angles of attack, although the spectral analysis of wall shear stress suggests the existence of flow structures having a similar spanwise length scale to the stall cells.
\end{abstract}

\section{Introduction}

Stall cells are three-dimensional separation patterns that can be observed on the suction side of airfoils near stall, initiated by the detachment of flow from the trailing edge. Their existence has been 
documented over the past half century $[1,2]$. Many researchers initially ascribed these 3D structures to the presence of walls in wind tunnels, but evidence suggests that the stall cell structures remain even when the aspect ratio of the wing ( $L / C$ where $L$ is the spanwise length and $C$ is the chord of the airfoil) is very high and that their length scale corresponds roughly to the streamwise dimension of the airfoil [3]. A thorough review of these early studies has been provided in [4]. There are variations in the terminology related to stall cells; they are often referred to as "mushroom-shaped" or "owl's eyes" structures.

The geometrical features of these flow patterns are known to be affected by the aspect ratio of the wing [5], Reynolds number [3], shape of the airfoil and the angle of attack [6]. The presence of stall cells could be related to the lift hysteresis, since their formation lowers the aerodynamic unsteady forces $[1,6]$. Moreover, the range of angles of attack in which the stall cells are observed is usually narrow. The topology of the stall cells has been described further in [7] as a couple of counter rotating vortices on the airfoil suction side developing in the streamwise direction, while the dynamic behavior of these patterns has been described in [8] depending on the Reynolds number, angle of attack and free stream turbulence variations.

The formation of stall cells has not been fully explained from a theoretical point of view; however, several possible physical mechanisms have been proposed to date. Winkelmann and Barlow $[4,5]$ proposed the first description of time-averaged morphology of stall cells, the so-called "tentative flow field" model. Weihs and Katz [9] suggested the Crow instability [10] to be at the origin of the stall cells emergence, and thereby derived a relationship to estimate the spanwise dimension of the cells. In the work of Bragg et al. [11] cellular patterns appeared together with a secondary low frequency pressure oscillation, inconsistent with the previous "tentative flow field" model. The effect of the Reynolds number has been investigated by Schewe [3], showing that laminar-turbulent transition could play a key role. Also, Rodriguez and Theofilis [12] found surface streamlines very similar to stall cells as a result of a global linear stability analysis of two-dimensional steady laminar separated flow superimposed by three-dimensional stationary disturbances. They have suggested that the formation of stall cells that can be observed in experiments at much higher Reynolds numbers is also due to a global instability, although their stability analysis was for a very low Reynolds number. 
More recently, the existence of multiple solutions to the Navier-Stokes equations has been demonstrated by Kamenetskiy et al. [13]. The flow patterns observed in some of these multiple solutions were similar to the stall cells, again suggesting that the formation of stall cells is quite sensitive to the stability of different flow patterns that could be observed in the post-stall range of angles of attack. This issue was discussed further by Spalart [14], who explained the spontaneous formation of stall cells using a periodic version of the lifting line theory. The uniform flow solution is not stable for a branch of the lift curve with a negative slope, resulting in a preferred pattern involving a finite number of cells. This is because the wing vortex interaction is self correcting with respect to spanwise perturbations only when the lift curve has a positive slope (i.e. $\partial c_{L} / \partial \alpha>0$, where $c_{L}$ and $\alpha$ are the lift coefficient and the angle of attack, respectively). Along the same line of thinking, Gross et al. [15] have recently proposed a physical mechanism deciding the spanwise spacing of stall cells. When a small separation zone appears at one spanwise location near the trailing edge, some localized flow can arise around the trailing edge from the pressure side to the suction side, leading to a local decrease in circulation due to the locally increased vertical velocity. Similarly, in a section between two zones of such a localized separation, there will be a local increase in circulation. These spanwise perturbations are damped as far as $\partial c_{L} / \partial \alpha>0$ but are amplified if $\partial c_{L} / \partial \alpha<0$, leading to the formation of stall cells. Based on this argument, Gross et al. [15] derived a simple mathematical model; they assumed harmonic disturbances along the spanwise direction and obtained a relationship between the spanwise spacing of stall cells and the slope of the lift curve.

Stall cells (or similar 3D flow patterns) have been observed in some recent numerical studies as well, often using the unsteady RANS and Detached-Eddy Simulation (DES) approaches. Bertagnolio et al. [16] performed simulations with a very high grid resolution in the spanwise direction (with 50 grid points per chord length), but their spanwise length of the domain was only 2.56 chords, enforcing periodic conditions at the side boundaries. Zaruskaya et al. [17] used a steady RANS solver in order to obtain stable 3D flow structures over a finite aspect-ratio wing with free spanwise ends (rather than an "infinite" wing with spanwise periodic conditions). Shur et al. [18] tested the URANS ability to predict 3D flow structures in the wake of $2 \mathrm{D}$ bluff bodies, revealing the sensitivity of flow structures to the turbulence model used and also, importantly, to the spanwise length of the computational domain. 
Gross and Fasel [19] employed a narrow computational domain with symmetric boundaries (instead of periodic boundaries) and observed a curved separation line, which the authors attributed to the presence of stall cells. Kamenetskiy et al. [13] have shown that these flow patterns may depend on the initial conditions. Also, Manolesos et al. [20] found that URANS simulations without an artificial spanwise perturbation produced various stall cells combinations, resembling the results of Kamenetskiy et al. [13]. A summary of experimental studies about stall cells is provided in table 1 , and that for computational studies is provided in table 2 .

The Reynolds number range in which stall cells are observed is typically around the order of one million [17], and since it is close to the operating range of wind turbine blades, this topic has recently been attracting the attention of many researchers in wind energy as well. An important issue from a practical point of view regarding the prediction of stall cells is its sensitivity to the mesh resolution in the spanwise direction [18]. This is a fundamentally important issue, for example, in the simulations of wind turbines with long blades, where a relatively coarse blade-spanwise resolution is often used in order to reduce computational costs. The formation of stall cells may affect the performance of both vertical axis turbines, where rotating blades tend to experience very high angles of attack, and horizontal axis turbines, where the progressive separation of flow from the root to the tip of the blades could be affected by the stall cells appearance. Furthermore, the recent developments of Unmanned Aerial Vehicles (UAV) have increased the interest in this phenomena observed in this range of Reynolds numbers.

Following these recent works, in this article we perform a numerical study on the formation of stall cells over a NACA 0012 airfoil at a Reynolds number of one million at high angles of attack, using URANS and DDES approaches. A key aspect of the present study is that we employ a very wide computational domain (10 chord length) to minimize the influence of spanwise periodic boundary conditions. We test four different spanwise resolutions to determine the minimum spanwise resolution required to capture the formation of stall cells. We also test various angles of attack with a small increment (every $0.5^{\circ}$ in the range between $17^{\circ}$ and $19^{\circ}$ ) to examine the aforementioned relationship between the slope of the lift curve and the spanwise spacing of stall cells. 
Table 1: Summary of experimental studies on stall cells.

\begin{tabular}{|c|c|c|c|c|c|c|c|}
\hline & Profile & $A R$ & $\operatorname{Re}\left(\cdot 10^{6}\right)$ & $C[\mathrm{~m}]$ & $\lambda / C$ & Sidewall Treatment & $\begin{array}{l}\text { Flow visualization } \\
\text { Technique }\end{array}$ \\
\hline $\begin{array}{l}\text { Moss and } \\
\text { Murdin [1] }\end{array}$ & NACA 0012 & 3.75 & $0.86,1.68$ & 0.407 & $\sim 2.5$ & Tunnel walls & Oil surface flow \\
\hline \multirow{2}{*}{$\begin{array}{l}\text { Gregory et } \\
\text { al. [2] }\end{array}$} & NACA 0012 & $\begin{array}{l}1.4-2.8 \\
6\end{array}$ & $\begin{array}{l}1.7-0.85 \\
0.76\end{array}$ & $\begin{array}{l}0.254- \\
0.127 \\
0.203\end{array}$ & $\begin{array}{c}\sim 2.5 \\
-\end{array}$ & Tunnel walls & \multirow[t]{2}{*}{ Oil drops } \\
\hline & NPL96192 & $\begin{array}{l}3.59 \\
3.29\end{array}$ & $\begin{array}{l}2.88 \\
3.14\end{array}$ & $\begin{array}{l}0.76 \\
0.83\end{array}$ & $\begin{array}{l}\sim 1.2 \\
\sim 1.6\end{array}$ & $\begin{array}{l}\text { Tunnel walls/ } \\
\text { End-plates }\end{array}$ & \\
\hline $\begin{array}{l}\text { Winkelman } \\
\text { and Barlow } \\
{[5]}\end{array}$ & Clark Y & $\begin{array}{l}3.5 \\
2.86 \\
3,6,9\end{array}$ & $\begin{array}{l}0.245 \\
0.26 \\
0.385\end{array}$ & 0.089 & $\begin{array}{l}- \\
- \\
3\end{array}$ & Free tips & Oil surface flow \\
\hline $\begin{array}{l}\text { Yon and } \\
\text { Katz [7] }\end{array}$ & NACA 0015 & $2-6$ & 0.62 & 0.152 & $1.5 \sim 2.3$ & Endplates & Tufts \\
\hline $\begin{array}{l}\text { Broeren and } \\
\text { Bragg [6] }\end{array}$ & $\begin{array}{l}\text { Ultra Sport } \\
\text { NACA } 2412 \\
\text { NACA } 64 \text { A010 } \\
\text { LRN-1007 } \\
\text { E374 }\end{array}$ & 2.8 & 0.3 & 0.305 & 2 & Tunnel walls & Tufts \\
\hline Schewe [3] & FX-77-W270 & $4-6$ & $0.32-10.0$ & $0.15-0.1$ & 2 & Tunnel walls & Oil surface flow \\
\hline $\begin{array}{l}\text { Elimelech et } \\
\text { al. [21] }\end{array}$ & $\begin{array}{l}\text { NACA } 0009 \\
\text { Eppler-61 }\end{array}$ & $2.5-5$ & 0.02 & $1.2,0.6$ & 1.5 & Endplates & - \\
\hline $\begin{array}{l}\text { Manolesos et } \\
\text { al. [8] }\end{array}$ & NTUA t18 & $1.5,2.0$ & $0.5-1.5$ & 0.6 & 1 & Endplates & Tufts \\
\hline $\begin{array}{l}\text { Manolesos et } \\
\text { al. [20] }\end{array}$ & NTUA t18 & 2 & 1 & 0.6 & 1 & Endplates & Tufts \\
\hline
\end{tabular}


Table 2: Summary of numerical studies on stall cells.

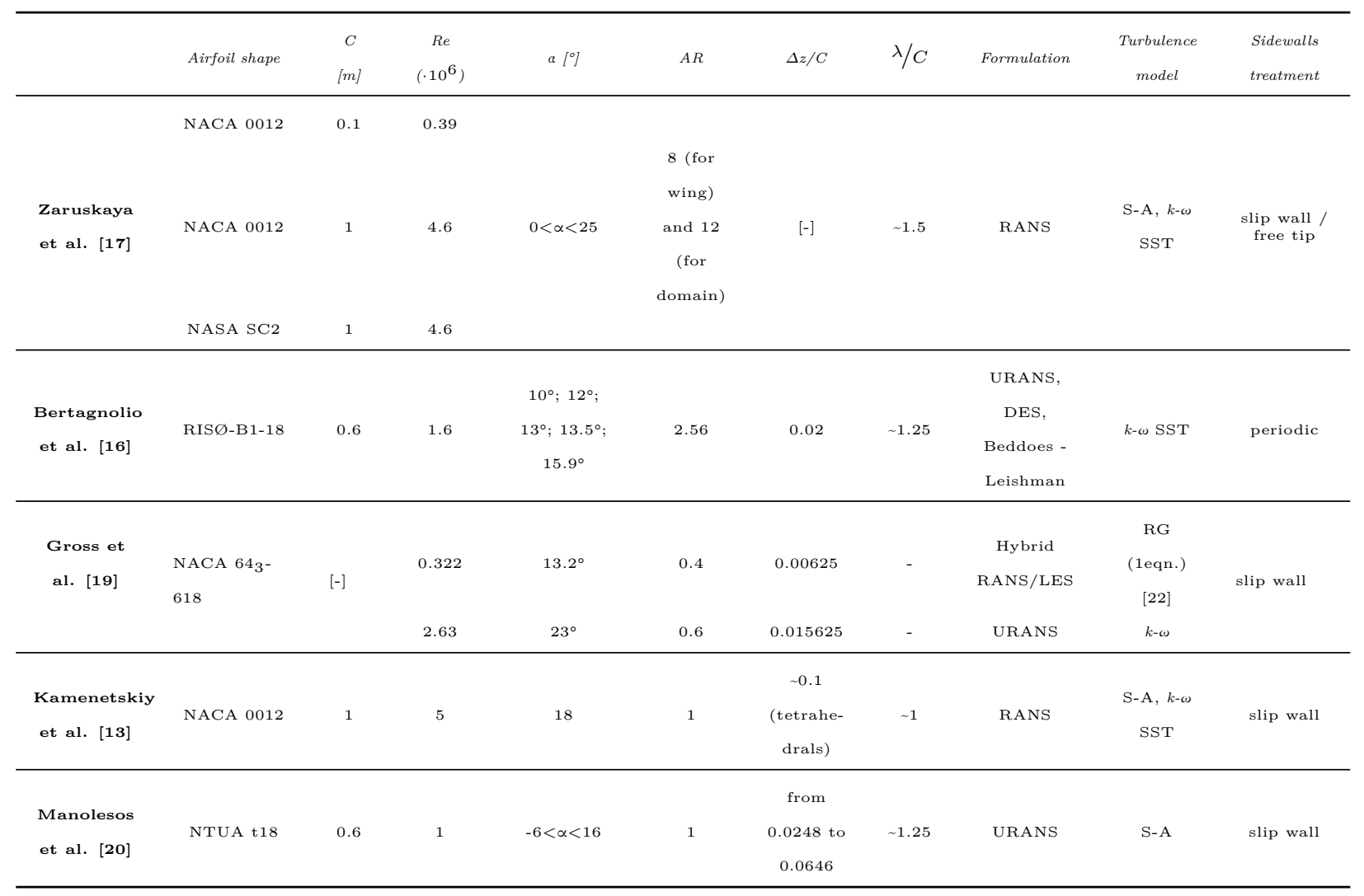

\section{Numerical Methods}

\subsection{Mesh and boundary conditions}

A series of preliminary 2D simulations has been carried out first to design a 2D mesh (with 50,000 elements in total) that yields mesh-independent 2D results. The mesh independence has been confirmed by doubling the number of nodes on each direction until the results in terms of lift and drag predictions did not change with further refinement. A summary of these 2D simulations is provided in table 3 . The first node distance from the airfoil surface is $8 \cdot 10^{-6}$ chord, which is small enough to guarantee $y^{+}<1$ everywhere on the airfoil to resolve the viscous sublayer sufficiently. A fully structured mesh 
is used in this study to minimize numerical diffusion and also to avoid any significant mesh-induced perturbation in the spanwise direction that could affect the formation of stall cells. The mesh is of the O-grid type and has been generated using ANSYS ICEM. The computational domain extends 30 chords in $x$ and $y$ directions from the leading edge of the airfoil, as can be seen in figure 1 . The time step size has been carefully evaluated, starting with $4 \cdot 10^{-3} \mathrm{~s}$, which is 0.06 of the characteristic time of the problem (given by the chord divided by the freestream velocity) and halving it until the lift and drag do not change with halving the time step further. For these tests, the angle of attack varied from 0 to $30^{\circ}$ with an increment of $5^{\circ}$. Based on these preliminary simulations we have decided to employ a time step size of $10^{-3} \mathrm{~s}$, equal to 0.015 of the characteristic time, and a mesh with 436 nodes around the airfoil. A close view of the $2 \mathrm{D}$ mesh created is presented in figure 2 .

Once the trustworthy 2D mesh had been created, it has been extruded in the spanwise direction for 10 chord length to create a 3D mesh. Four different 3D meshes have been generated with 10, 20, 50 and 200 nodes, respectively, along the spanwise direction. For the spanwise ends of the domain, periodic boundary conditions are imposed. For the inlet boundary (shown by red in figure 1) fixed velocity components are prescribed depending on the angle of attack, whereas for the outlet boundary (shown by blue in figure 1) zero pressure gradient is imposed. The inlet values of turbulence intensity and viscosity ratio are fixed to $5 \%$ and 10, respectively; however, since the inlet boundary is quite far from the airfoil, turbulence intensity decreases down to $0.1 \%$ at the airfoil location. A summary of the 3D meshes used in this study is provided in table 4. Although not shown here for brevity, a further validation study was conducted with a narrower spanwise domain size of 5 chord length, which produced results similar to the wide domain (10 chord length) cases. 

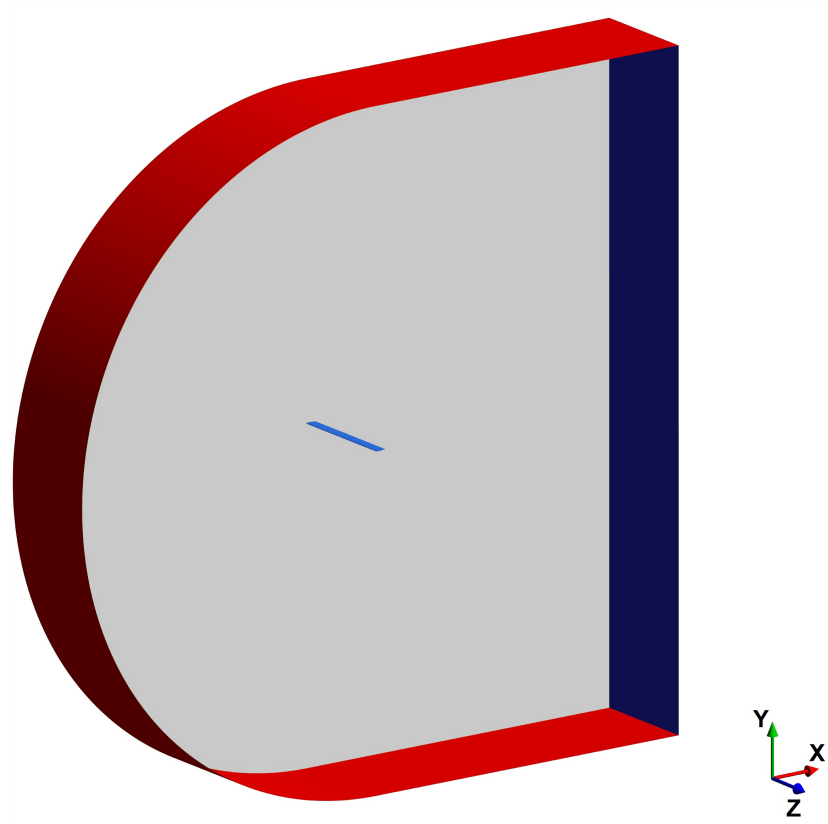

Figure 1: Computational domain: red for inlet, blue for outlet. Front and back planes are periodic.

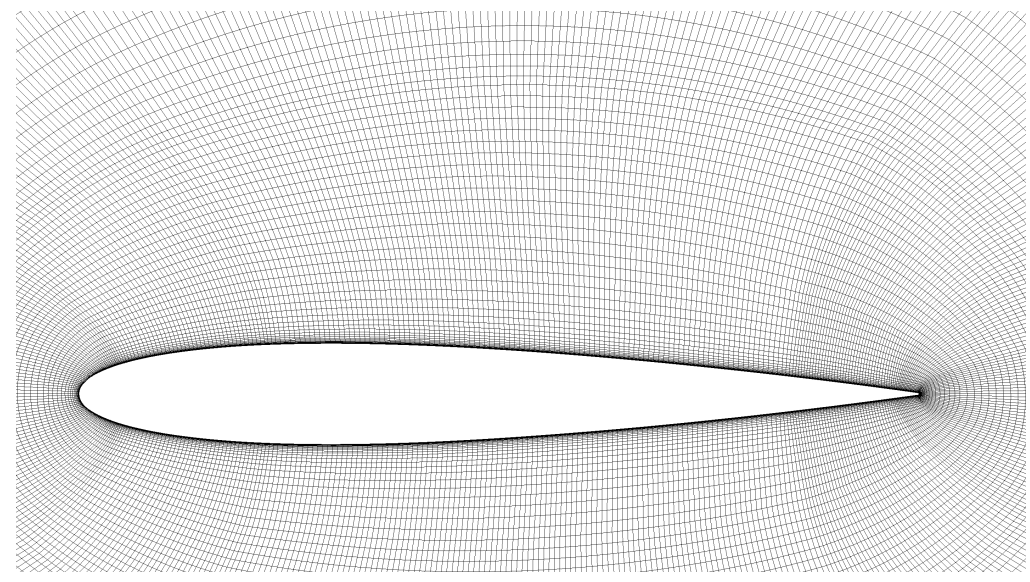

Figure 2: Close-up view of the 2D mesh around the NACA 0012 airfoil. 
Table 3: 2D meshes used for evaluating grid independence.

\begin{tabular}{ccccc}
\hline$X, Y$ nodes & $\Delta x^{+}$ & $\Delta y^{+}$ & elements & $\begin{array}{c}\text { computed lift } \\
\text { at a }=5-10-15\end{array}$ \\
\hline 142 & $\sim 800$ & $\sim 0.5$ & 12500 & $0.530-0.986-1.01$ \\
218 & $\sim 400$ & $\sim 0.5$ & 25000 & $0.536-1.02-1.33$ \\
436 & $\sim 200$ & $\sim 0.5$ & 50000 & $0.538-1.03-1.37$ \\
654 & $\sim 130$ & $\sim 0.5$ & 75000 & $0.538-1.03-1.38$ \\
\hline
\end{tabular}

Table 4: 3D meshes used in the present study.

\begin{tabular}{cccccccc}
\hline \multirow{2}{*}{ Name } & $X, Y$ & $z$ & $\Delta z / C$ & $\Delta x^{+}$ & $\Delta y^{+}$ & $\Delta z^{+}$ & $\begin{array}{c}\text { elements } \\
\left(\cdot 10^{6}\right)\end{array}$ \\
\hline nodes & nodes & & 1 & $\sim 200$ & $\sim 0.5$ & $\sim 4.3 \cdot 10^{4}$ & 0.5 \\
N10 & 436 & 10 & 0.5 & $\sim 200$ & $\sim 0.5$ & $\sim 2.1 \cdot 10^{4}$ & 1 \\
N20 & 436 & 20 & 0.2 & $\sim 200$ & $\sim 0.5$ & $\sim 8.5 \cdot 10^{3}$ & 2.5 \\
N200 & 436 & 50 & 0.05 & $\sim 200$ & $\sim 0.5$ & $\sim 2.1 \cdot 10^{3}$ & 10 \\
\hline
\end{tabular}

\subsection{Turbulence models and numerical procedure}

This study, employing the Unsteady Reynolds-Averaged Navier Stokes (URANS) and Delayed Detached Eddy Simulation (DDES) approaches, has been conducted using the commercial code ANSYS FLUENT 15. The URANS equations need a closure for the Reynolds stress tensor, i.e. a turbulence model. In this study we employ the $k$ - $\omega$ SST model proposed by Menter [23], as it has been extensively tested in literature for this type of flow. Since the $k$ - $\omega$ SST model functions as a $k$ - $\omega$ model near the wall, we can solve the flow field inside the boundary layer without using any wall functions.

The DDES approach is a modification of the Detached Eddy Simulation (DES), which was proposed first by Spalart in 1997 [24] and was applied to a 3D flow in 1999 [25]. The DES approach aims to blend the RANS and LES advantages, using the former inside the boundary layer, where the mesh resolutions in the wall-parallel directions would be a severe limit for LES, and the latter in the detached flow. The original version of DES had some problems, especially when used with an intermediate mesh resolution near the wall, i.e. when the resolution is fine enough to switch to LES mode but not fine enough to correctly calculate the Reynolds stresses, leading to the Modeled Stress Depletion [26, 27]. The DDES approach was developed to avoid the LES mode activation in regions inside the boundary 

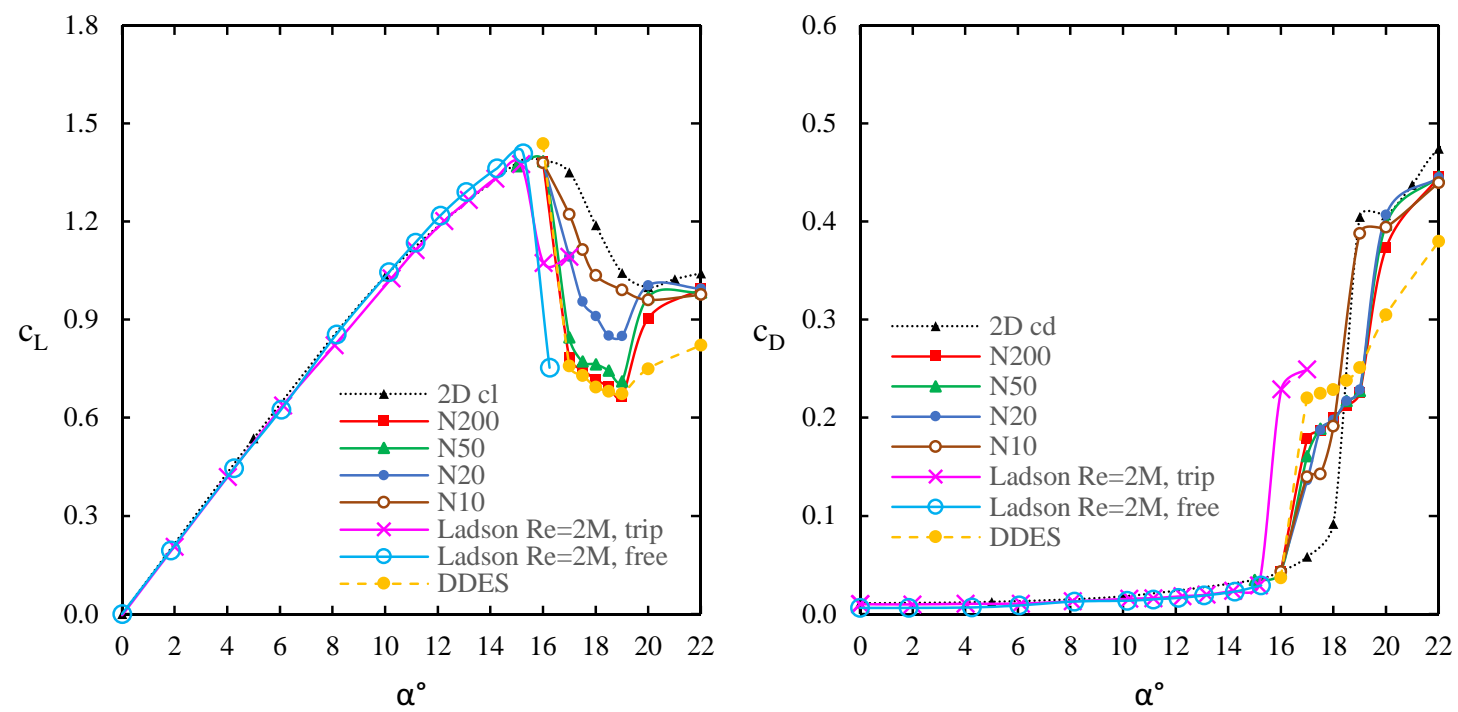

Figure 3: Lift and drag curves. All computational results are at $\operatorname{Re}=1 \cdot 10^{6}$.

layer, even if the mesh resolution is fine compared to the local physical length scale [28]. Further details of the DDES approach used in this study, which is based on the $k$ - $\omega$ SST model, can be found in the appendix of [29]. All DDES computations in this study are performed using the finest 3D mesh (the N200 mesh in table 4).

For the numerical schemes, a second order upwind scheme has been used for all variables in both URANS and DDES, with the exception of the convective terms in the DDES momentum equations, where a bounded central differencing scheme is adopted for its lower diffusivity. With regards to the time discretization a second order implicit scheme has been used, and the SIMPLE algorithm [30] is employed for the pressure velocity coupling. For each time step the normalized residuals on all equations have been ensured to fall below $10^{-5}$, whereas to evaluate the convergence of the unsteady solution, temporal variations of the lift and drag forces have been monitored. Each simulation has been run until a statistically stable solution was kept long enough (at least for 4096 time steps, which correspond to about 4.1 seconds or 61 chord flow-through times). Each simulation has been initialized with the entire flow field being equal to the inlet boundary conditions. 




Figure 4: Instantaneous skin friction lines together with contours of streamwise wall shear stress, computed from the URANS results. 


\section{Results and discussion}

\subsection{URANS}

We first present the lift and drag curves for all simulations performed, which are shown in figure 3. Also plotted in this figure for comparison are the experimental data reported by Ladson [31]. From this figure, it is clear that the influence of the third dimension is negligible for all angles of attack below $16^{\circ}$, at which the lift coefficient reaches its maximum. This is because the flows predicted by these URANS simulations are fully two-dimensional at any angles of attack below $16^{\circ}$. Hence the spanwise mesh resolution does not affect the flow predicted at these angles of attack.

As we increase further the angle of attack, a steep decrease in lift follows together with an abrupt increase in drag, i.e. the airfoil stalls. This behavior has also been found in experimental measurements [31]; however, here the effects of spanwise mesh resolution on the numerical results are significant. It can be seen that the finer the spanwise resolution, the sharper the drop of the lift, although the two finest meshes (N50 and N200) yield similar results which are also close to the DDES results to be discussed later in Section 3.2. The steep drop of lift around $17^{\circ}$ is followed by a further (but less steep) lift decrease, which continues till $19^{\circ}$. Above this high angle of attack the curve presents a positive slope again and the influence of spanwise mesh resolution gradually decreases and almost disappears at $22^{\circ}$, even though a small difference remains between the $2 \mathrm{D}$ and $3 \mathrm{D}$ results.

For the drag curves, it is again possible to identify three distinctive angle-of-attack ranges or branches. First, the drag remains small till $16^{\circ}$, and then an abrupt increase in drag occurs around $17^{\circ}$ (except for the $2 \mathrm{D}$ case). From $17^{\circ}$ to $19^{\circ}$, the increase in drag exhibits a certain linearity, and another steep rise follows from $19^{\circ}$ up to $22^{\circ}$, where the effect of spanwise mesh resolution becomes insignificant.

As will be described below, the analysis of flow field around the airfoil can explain these three branches observed in the lift and drag curves, i.e. the transitions of lift and drag curves from one branch to another are directly related to the formation and disappearance of stall cells above the airfoil. These flow structures consist of pairs of counter rotating streamwise vortices. An effective 
way to confirm their presence is to plot the skin friction lines as shown in figure 4, which also shows contours of the streamwise wall shear stress $\tau_{x}$ on the airfoil surface.

This post-process produces a result analogous to the oil-flow technique widely used in wind tunnel experiments for flow visualization, although the contours of $\tau_{x}$ presented here give some additional information. Note that the positive zones of $\tau_{x}$ roughly correspond to attached flow regions, whereas the negative areas roughly correspond to separated flow regions.

From the right side to left side of figure 4, the spanwise mesh resolution increases from $\mathrm{N}=20$ to 200 (where $\mathrm{N}$ is the number of nodes along spanwise direction) as noted at the upper left corner of each picture. As can be seen, the formation of 3D flow patterns coincides with the drop in lift and the rise in drag, in agreement with the findings of Broeren et al. [6]. From $17^{\circ}$ to $18.5^{\circ}$ the flow field is dominated by large 3D flow structures having a spanwise length scale comparable to their streamwise length scale. The N20 mesh exhibits a strong sensitivity of the size of stall cells to the angle of attack, presumably due to the coarse spanwise mesh resolution not sufficient to capture the $3 \mathrm{D}$ flow physics properly. On the N10 mesh we did not observe any stall cells.

In the range of angles of attack from $17^{\circ}$ to $18.5^{\circ}$ the flow patterns and positions of the stall cells were nearly stable. This finding is in agreement with Gross et al. [15], who suggested that a negative slope of lift curve (as observed in the present study from $17^{\circ}$ to $19^{\circ}$ ) is required to allow the formation of stall cells. Furthermore, our numerical results obtained for the N200 mesh support the relationship suggested (as the "continuous model") by Gross et al. [15] between the spanwise spacing of stall cells and the negative slope of the lift curve, which can be written as follows:

$$
\frac{\lambda}{c}=-\frac{\pi}{4} \frac{\partial c_{L}}{\partial \alpha}
$$

where $\lambda$ is the average spanwise spacing of stall cells (i.e. entire width divided by the number of stall cells). Using the $\partial c_{L} / \partial \alpha$ obtained from the N200 lift curve, the relationship in (1) predicts a non-dimensionalised stall cell size of $\lambda / c \sim 1.8$ for the $18^{\circ}$ case, whereas the actual size of stall cells observed in the URANS solution for this angle of attack is $\lambda / c \sim 1.7$. Note that the unit of the angle 

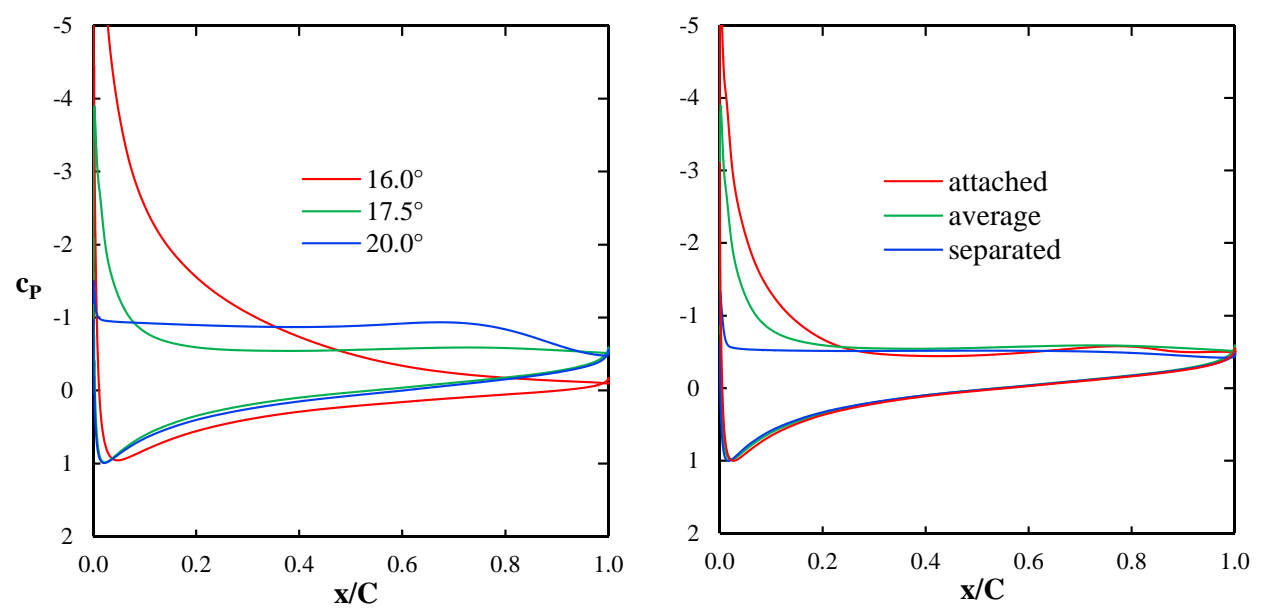

Figure 5: Spanwise-averaged pressure profiles for three angles of attack corresponding to the pre- $\left(16.0^{\circ}\right)$, during $\left(17.5^{\circ}\right)$ and post-stall $\left(20.0^{\circ}\right)$ cases (left) and profiles for the $17.5^{\circ}$ case at two different spanwise locations corresponding to the attached and separated flow regions (right) .

of attack $a$ in (1) is radian.

To have a deeper understanding of how stall cells affect the airfoil performance, the mean static pressure profiles around the airfoil (averaged in the spanwise direction) are presented in figure 5 (left) for three different angles of attack, namely $16.0^{\circ}$ (pre-stall), $17.5^{\circ}$ (during the stall) and $20.0^{\circ}$ (poststall). On the pressure side of the airfoil, static pressure does not change with the angle of attack, whereas on the suction side the difference between the three cases is evident. At $16^{\circ}$ the pressure profile is a typical profile observed before the stall, generating a high lift mainly due to the large pressure difference around the leading edge. Of particular interest is the difference between the $17.5^{\circ}$ and $20.0^{\circ}$ cases, showing why the lift coefficient predicted at $17.5^{\circ}$ is lower than that predicted at $20.0^{\circ}$, even though the flow is fully separated from the leading edge in the latter case. The suction predicted on the airfoil upper surface is stronger when the flow is fully separated compared to the case with stall cells, considering the spanwise averaged value. This can be explained further in figure 5 (right), which shows pressure profiles around the airfoil at $17.5^{\circ}$ at two different spanwise locations (corresponding to where the flow is attached and separated) together with the spanwise averaged profile. It can be seen that the attached region creates stronger suction but only near the leading edge $(x / C<0.2)$. This explains the very low lift coefficient predicted for the case with stall cells. 

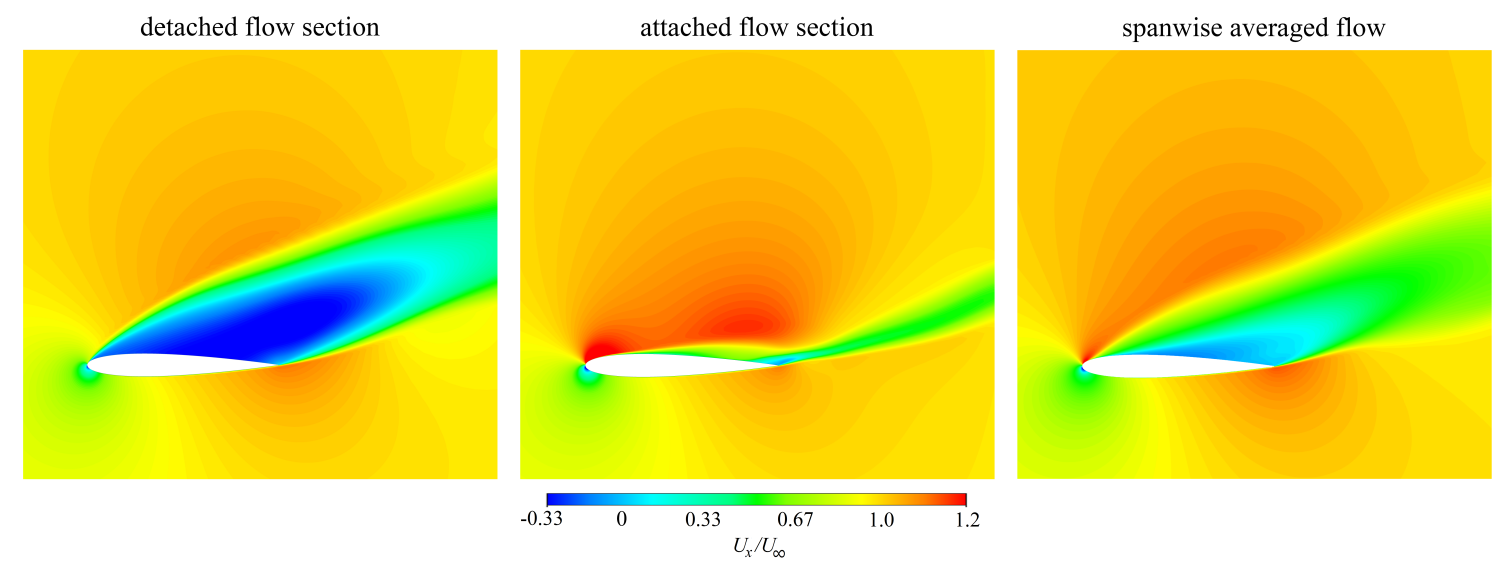

Figure 6: Instantaneous streamwise velocity contours for the N200 URANS $17.5^{\circ}$ case, for a separated flow section, attached flow section and spanwise averaged.

To understand further the predicted performance of the airfoil with stall cells at $17.5^{\circ}$, streamwise velocity contours at two spanwise locations (corresponding to the "attached" and "separated" regions) are plotted in figure 6 , together with the spanwise averaged contours. What is clearly visible is that the mean flow pattern is closer to the separated pattern rather than the attached one, since the separated regions (stall cells) are much larger than the attached regions (gaps between the stall cells). The structures of the stall cells can be seen more clearly in figure 7, which shows contours of instantaneous streamwise velocity and vorticity at several chordwise locations. From this figure it is possible to count the number of stall cells to evaluate $\lambda$ : since the span of the computational domain is $10 C$ and 6 structures can be seen, we can estimate $\lambda / C \approx 10 / 6=1.67$ for the $17.5^{\circ}$ case. The presence of two additional small structures or undulations on each cell structure indicates the presence of a higher frequency mode, which can be seen at $x / C=0.2,0.4$ and 0.6 but almost disappears at $x / C=0.8$. A pair of counter-rotating high vorticity regions can be seen along the surface of each stall cell at $x / C$ $=0.2$ and 0.4 , but another pair emerges inside each cell (very close to the wall surface) at $x / C=0.6$ and 0.8 .

Taking advantage of the structured mesh, which has a uniform spanwise grid spacing across the entire domain, we have performed a Fourier transform of the signal of $\tau_{x}$ (obtained from the N200 results) on the airfoil upper surface along several lines parallel to the spanwise direction. This method 


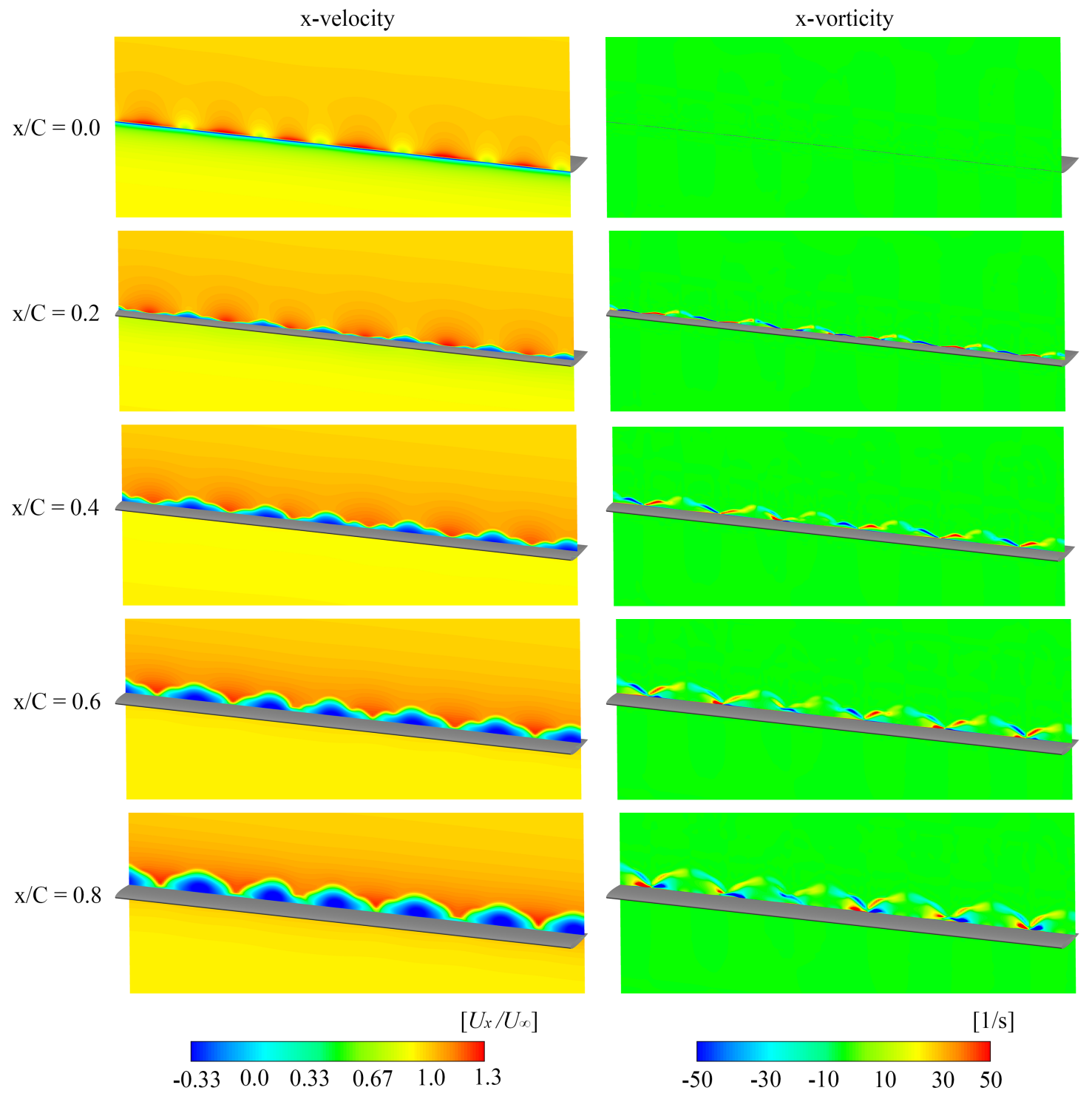

Figure 7: URANS results for $17.5^{\circ}$ : instantaneous stream-wise velocity and streamwise vorticity contours at several $x / C$. 
allows a more accurate evaluation of the stall cells dimension. The results of this Fourier transform at several chordwise locations have been averaged to obtain the suction side average spectrum, which is presented in figure 8 for four different angles of attack. It is evident that the main peaks identified by the Fourier transform are located in the spatial frequency range of $0.55<1 / \lambda<0.70$, which corresponds to the range of $1.4<\lambda<1.8$, confirming the previous visual estimation of the stall cell spacing.

At $\alpha=17^{\circ}$, the spectrum of $\tau_{x}$ shows another (less clear) peak at $1 / \lambda=0.313$, which reflects the existence of larger and more complex flow structures at this angle of attack (as can be seen in figure 4) compared to those obtained at higher angles of attack. At this particular angle of attack we have initially obtained a quasi-stable 2D solution without stall cells but after more than 20 seconds of simulation time the solution has started changing dramatically to another stable solution with stall cells, as can be seen from the time variations of lift and drag in figure 9. For all other angles of attack the process to reach the final solution was straightforward and no such "pseudo-solutions" or different "basins of attraction" [13] were observed before convergence. As discussed in [13] the appearance of these types of phenomena seems to be closely related to the stability of flow separated from a smooth body, especially near the stall angle of attack for the case of an airfoil. One possible explanation for the appearance of quasi-stable 2D solution in the current URANS simulation is due to the effect of turbulent viscosity stabilizing the mean flow (during the initial stage of the simulation) and extending the lifetime of 2D separated flow pattern which is only weakly unstable. Since both lift and drag coefficients obtained are significantly different between the quasi-stable 2D solution and the final 3D solution, a special care needs to be taken when judging the convergence of URANS solutions for this type of flow.

As the angle of attack increases from $17^{\circ}$ to $18^{\circ}$, the spectrum becomes narrower around the peak, whereas above the $18^{\circ}$ the spectrum starts to present some additional peaks at higher frequencies. As can be seen in figure 4 , at $18.5^{\circ}$ some secondary (shorter) structures appear near the leading edge and they remain till $19^{\circ}$, above which the stall cells mostly disappear and the flow is almost fully separated. 



Figure 8: Spanwise spectrum of the instantaneous streamwise wall shear stress (averaged across the airfoil upper surface).



Figure 9: Lift and drag variations during the URANS N200 computation at $17.0^{\circ}$. 


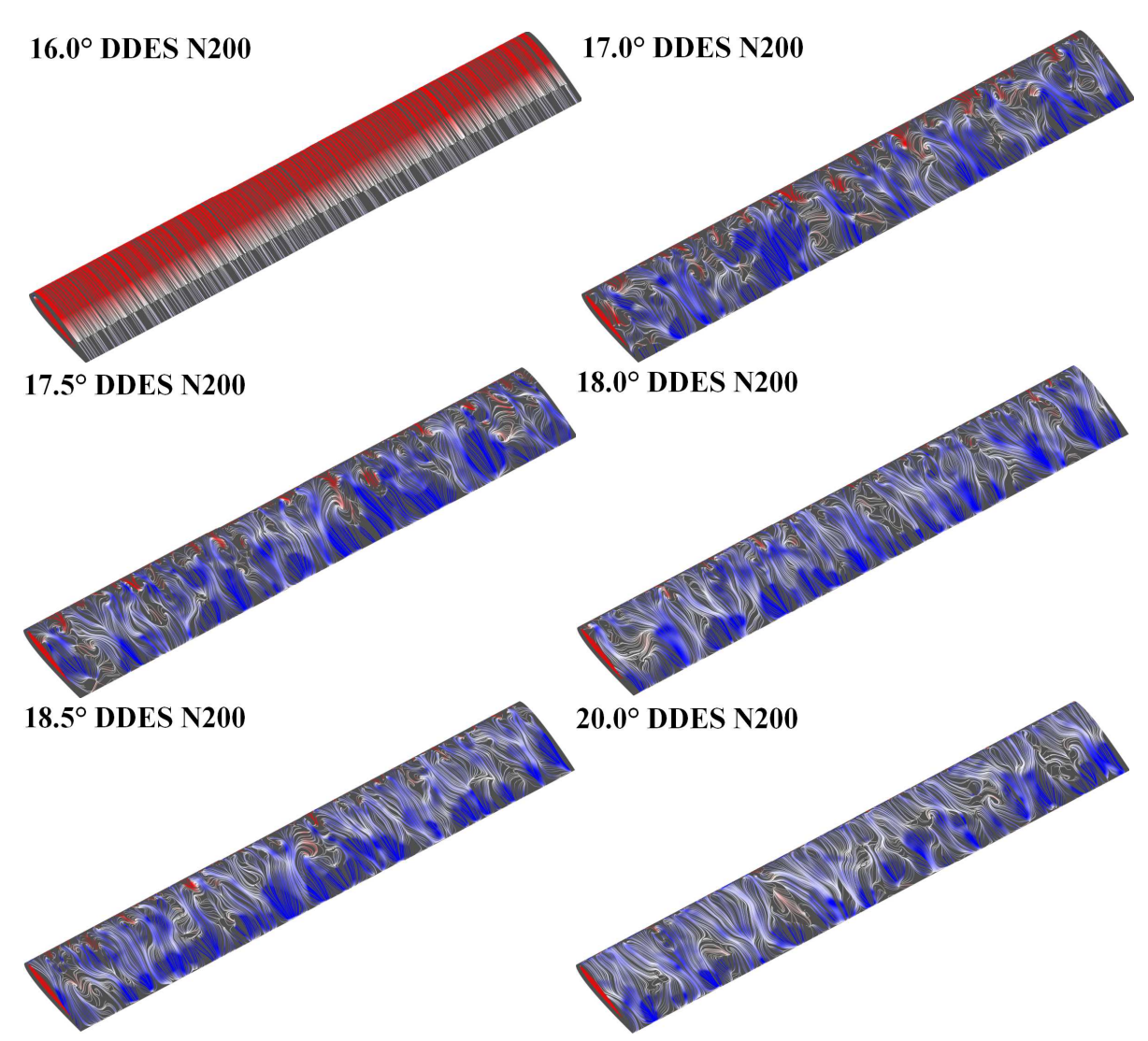

Figure 10: Instantaneous skin friction lines together with contours of streamwise wall shear stress, computed from the DDES results.

\section{2. $D D E S$}

The DDES approach has been employed only with the N200 mesh. One potential benefit of using the $k$ - $\omega$ SST model in DDES is that, unlike the S-A version of DDES, the switch between the LES mode and the URANS mode is adjusted dynamically depending on the unsteady flow solution. This is due to the difference in the length scale definition: the S-A model defines the length scale simply based on the distance from the closest wall, i.e. it depends only on the geometry, whereas the $k-\omega \mathrm{SST}$ model defines the length scale based on $k$ and $\omega$, i.e. it is solution-dependent.

As shown earlier in figure 3, the lift curve predicted by DDES agrees well with URANS (using the same N200 mesh) up to the angle of attack of $19^{\circ}$, but then a large discrepancy is observed in 
the third branch (post-stall range), where the lift predicted by DDES is significantly lower. As for the drag curve, it can be seen that the overall pattern is again similar to the URANS predictions; however the drag predicted by DDES is higher in the second branch and lower in the third branch compared to URANS. It is worth noting that the drag predicted by URANS increases suddenly and significantly from the second branch to the third branch, reflecting the sudden change of flow pattern (i.e. disappearance of stall cells) over the airfoil, unlike the DDES predictions.

With regard to the formation of stall cells, the good agreement between the URANS and DDES lift predictions suggests the existence of stall cells in the DDES solutions as well. However, as shown in figure 10, it is difficult to visually recognize the structures of stall cells in the DDES solutions, since DDES resolves smaller-scale turbulent flow structures as well. To understand better the flow structures above the airfoil, here we compare the spectrum of $\tau_{x}$ along the airfoil upper surface between the URANS and DDES, to see if there are any common peaks. As shown in figure 8, even though the DDES spectrum is much richer than the URANS spectrum, it exhibits a similar main peak to that observed in the URANS spectrum, suggesting the existence of large-scale flow structures similar to stall cells.

Although the flow patterns visualized in figure 10 are rather complex, we can still recognize some locally attached flow regions near the leading edge, similarly to what we observed between stall cells in the URANS results. Another important difference between the URANS and DDES results is the flow pattern predicted at $20^{\circ}$ (and higher). Comparing figure 10 with figure 4 , we can see that DDES predicted complex $3 \mathrm{D}$ flow patterns even at $20^{\circ}$, whereas URANS predicted nearly $2 \mathrm{D}$ flow patterns, explaining the significant difference in the prediction of lift and drag in the post-stall range.

\section{Conclusions}

In this study we have numerically investigated the formation of stall cells and their influence on the aerodynamic performance of a NACA 0012 airfoil at a Reynolds number of one million, using a very wide (10 chord length) computational domain. We have employed URANS and DDES approaches, both of which have captured a sudden decrease in lift and increase in drag between $16^{\circ}$ and $17^{\circ}$ angles of attack, accompanied by a significant change of flow patterns from 2D to 3D. The URANS simulations 
revealed clearly defined stall cell structures between $17^{\circ}$ and $19^{\circ}$ with their spanwise spacing of about 1.4 to 1.8 chord length, which is in good agreement with the relationship recently proposed by Gross et al. [15]. To the authors' knowledge, this is the first time that the above theoretical relationship between the stall cell size and the slope of the lift curve has been confirmed by a carefully designed set of 3D numerical simulations using a sufficiently wide computational domain for an ideal "infinitelylong" wing (i.e. without wing-tip/end effects) at a high Reynolds number. The DDES predicted much more complex 3D flow structures over the airfoil, although the spectral analysis of wall shear stress suggested the existence of flow structures having a similar length scale to the stall cells observed in the URANS simulations.

For the URANS simulations, we have tested four different spanwise mesh resolutions to demonstrate their influence on the formation of stall cells and also on the lift and drag. It has been shown that the minimum resolution required to properly capture the formation of stall cells is about 0.2 chord length (which roughly corresponds to 10 to $15 \%$ of the stall cell size). Since the formation of stall cells tends to affect the prediction of lift and drag significantly, this minimum requirement of spanwise mesh resolution is of practical importance, especially when simulating a large aspect ratio wing or a long wind-turbine blade.

In this study we did not investigate the influence of different turbulence models or different initial flow conditions on the formation of stall cells. These issues need to be investigated further in future studies.

\section{Acknowledgment}

The first author would like to acknowledge the support of the Industrial Engineering Department of the University of Rome "Tor Vergata", which allowed a five-month visit to Cranfield University from June to October 2015 to conduct this study. 


\section{References}

[1] G. F. Moss and P. M. Murdin. Two-Dimensional low-speed tunnel tests on the NACA 0012 section including measurements made during pitching oscillations at the stall. RAE tech report TR 68104, 1968.

[2] N. Gregory, V. G. Quincey, C. L. O' Reilly, and D. J. Hall. Progress Report on Observations of Three-Dimensional Flow Patterns Obtained During Stall Development on Airfoils and on the Problems of Measuring Two-Dimensional Characteristics. Aeronautical Research Council CP, $1146,1971$.

[3] G. Schewe. Reynolds-number effects in flow around more-or-less bluff bodies. Journal of Wind Engineering and Industrial Aerodynamics, 89(14-15):1267-1289, December 2001.

[4] A. E. Winkelmann. An experimental study of mushroom shaped stall cells. In AIAA/ASME 3rd Joint Thermophysics, Fluids, Plasma and Heat Transfer Conference, AIAA-82-0942. American Institute of Aeronautics and Astronautics, June 1982.

[5] A. E. Winkelman and J. B. Barlow. Flowfield Model for a Rectangular Planform Wing beyond Stall. AIAA Journal, 18(8):1006-1008, August 1980.

[6] A. P. Broeren and M. B. Bragg. Spanwise Variation in the Unsteady Stalling Flowfields of TwoDimensional Airfoil Models. AIAA Journal, 39(9):1641-1651, September 2001.

[7] S. A. Yon and J. Katz. Study of the Unsteady Flow Features on a Stalled Wing. AIAA Journal, 36(3):305-312, March 1998.

[8] M. Manolesos and S. G. Voutsinas. Geometrical characterization of stall cells on rectangular wings. Wind Energy, (17):1301-1314, May 2013.

[9] D. Weihs and J. Katz. Cellular patterns in poststall flow over unswept wings. AIAA Journal, 21(12):1757-1759, December 1983. 
[10] S. C. Crow. Stability theory for a pair of trailing vortices. AIAA Journal, 8(12):2172-2179, December 1970.

[11] B. M. Bragg, D. C. Heinrich, F. A. Balow, and K. B. M. Q. Zaman. Flow oscillation over an airfoil near stall. AIAA Journal, 34(1):199-201, January 1996.

[12] D. Rodriguez and V. Theofilis. On the birth of stall cells on airfoils. Theoretical and Computational Fluid Dynamics, 25(1-4):105-117, June 2011.

[13] D. S. Kamenetskiy, J. E. Bussoletti, C. L. Hilmes, V. Venkatakrishnan, L. B. Wigton, and F. T. Johnson. Numerical Evidence of Multiple Solutions for the Reynolds-Averaged Navier-Stokes Equations. AIAA Journal, 52(8):1686-1698, August 2014.

[14] P. R. Spalart. Prediction of Lift Cells for Stalling Wings by Lifting-Line Theory. AIAA Journal, 52(8):1817-1821, August 2014.

[15] A. Gross, H. Fasel, and M. Gaster. Criterion for Spanwise Spacing of Stall Cells. AIAA Journal, 53(1):272-274, January 2015.

[16] F. Bertagnolio, N. N. Sorensen, and F. Rasmussen. New Insight Into the Flow Around a Wind Turbine Airfoil Section. Journal of Solar Energy Engineering, 127(2):214, 2005.

[17] T. Zarutskaya and R. Arieli. On Vortical Flow Structures at Wing Stall and Beyond. In 35th AIAA Fluid Dynamics Conference and Exhibit, volume AIAA 2005-4913. American Institute of Aeronautics and Astronautics, June 2005.

[18] M. Shur, P. R. Spalart, K. D. Squires, M. Strelets, and A. Travin. Three-Dimensionality in Reynolds-Averaged Navier-Stokes Solutions Around Two-Dimensional Geometries. AIAA Journal, 43(6):1230-1242, June 2005.

[19] A. Gross and H. Fasel. Numerical Investigation of Separation for Airfoils. In 41st AIAA Fluid Dynamics Conference and Exhibit, AIAA 2011-3438. American Institute of Aeronautics and Astronautics, June 2011. 
[20] M. Manolesos, G. Papadakis, and S. G. Voutsinas. Experimental and computational analysis of stall cells on rectangular wings: Experimental and CFD analysis of stall cells. Wind Energy, 17(6):939-955, June 2014.

[21] Y. Elimelech, R. Arieli, and G. Iosilevskii. The three-dimensional transition stages over the NACA-0009 airfoil at Reynolds numbers of several ten thousand. Physics of Fluids, 24(2):024104, 2012.

[22] C. Langhe, J. Bigda, K. Lodefier, and E. Dick. One-Equation RG Hybrid RANS/LES Modelling. In S. Peng and W. Haase, editors, Advances in Hybrid RANS-LES Modelling, volume 97, pages 97-106. Springer Berlin Heidelberg, Berlin, Heidelberg, 2008.

[23] F. R. Menter. Two-equation eddy-viscosity turbulence models for engineering applications. AIAA Journal, 32(8):1598-1605, August 1994.

[24] P. R. Spalart, W-H. Jou, M. Strelets, and S. R. Allmaras. Comments on the feasibility of LES for wings, and on a hybrid RANS/LES approach. In Advances in DNS/LES, 1st AFOSR Int. Conf. On DNS/LES. Greyden Press, August 1997.

[25] M. Shur, P. R. Spalart, M. Strelets, and A. Travin. Detached-eddy simulation of an airfoil at high angle of attack. In Engineering Turbulence Modelling and Experiments 4, pages 669-678. Elsevier, 1999.

[26] P. R. Spalart. Strategies for turbulence modelling and simulations. International Journal of Heat and Fluid Flow, 21(3):252-263, June 2000.

[27] F. R. Menter, M. Kuntz, and R. Langtry. Ten years of industrial experience with the SST turbulence model. Turbulence, Heat and mass transfer, 4, 2003.

[28] P. R. Spalart, S. Deck, M. L. Shur, K. D. Squires, M. K. Strelets, and A. Travin. A New Version of Detached-eddy Simulation, Resistant to Ambiguous Grid Densities. Theoretical and Computational Fluid Dynamics, 20(3):181-195, July 2006. 
[29] M. S. Gritskevich, A. V. Garbaruk, J. Schutze, and F. R. Menter. Development of DDES and IDDES Formulations for the $\mathrm{k}-\omega$ Shear Stress Transport Model. Flow, Turbulence and Combustion, 88(3):431-449, April 2012.

[30] S. V. Patankar. Numerical heat transfer and fluid flow. Series in computational methods in mechanics and thermal sciences. Hemisphere Publ. Co, New York, 1980.

[31] C. Ladson. Effects of independent variation of mach and Reynolds numbers on the low-speed aerodynamic characteristics of the naca 0012 airfoil section. NASA Technical Memorandum 4074, October 1988. 